\title{
Formation of diclofenac and sulfamethoxazole reversible transformation products in aquifer material under denitrifying conditions: Batch experiments
}

\author{
Manuela Barbieri ${ }^{\text {a,* }}$, Jesús Carrera ${ }^{\text {a }}$, Carlos Ayora ${ }^{\text {a }}$, Xavier Sanchez-Vila ${ }^{\text {b }}$, Tobias Licha ${ }^{\text {c }}$, Karsten Nödler ${ }^{\text {, }}$ \\ Victoria Osorio ${ }^{\mathrm{d}}$, Sandra Pérez ${ }^{\mathrm{d}}$, Marianne Köck-Schulmeyer ${ }^{\mathrm{d}}$, Miren López de Alda ${ }^{\mathrm{d}}$, Damià Barceló ${ }^{\mathrm{d}, \mathrm{e}}$ \\ a GHS, Dept. of Geosciences, Institute of Environmental Assessment and Water Research, IDAEA-CSIC, Jordi Girona 18-26, 08034 Barcelona, Spain \\ b GHS, Dept. of Geotechnical Engineering and Geo-Sciences, Technical University of Catalonia, Jordi Girona 1-3, Modul D-2, 08034 Barcelona, Spain \\ ${ }^{c}$ Hydrochemistry Group, Dept. of Applied Geology, Geoscience Centre of the University of Göttingen, Goldschmidtstr. 3, 37077 Göttingen, Germany \\ d Dept. of Environmental Chemistry, Institute of Environmental Assessment and Water Research, IDAEA-CSIC, Jordi Girona 18-26, 08034 Barcelona, Spain \\ e Catalan Institute for Water Research (ICRA), Parc Científic i Tecnològic de la Universitat de Girona, Edifici H2O, 17003 Girona, Spain
}

\section{A R T I C L E I N F O}

\section{Article history}

Received 19 October 2011

Received in revised form 22 February 2012

Accepted 23 February 2012

Available online 23 April 2012

\section{Keywords:}

Microcosm experiments

Aromatic amines

Nitrite

Transformation products

Reversible process

\begin{abstract}
A B S T R A C T
Soil-aquifer processes have proven to work as a natural treatment for the attenuation of numerous contaminants during artificial recharge of groundwater. Nowadays, significant scientific effort is being devoted to understanding the fate of pharmaceuticals in subsurface environments, and to verify if such semipersistent organic micropollutants could also be efficiently removed from water. In this context we carried out a series of batch experiments involving aquifer material, selected drugs (initial concentration of $1 \mu \mathrm{g} / \mathrm{L}$ and $1 \mathrm{mg} / \mathrm{L}$ ), and denitrifying conditions. Diclofenac and sulfamethoxazole exhibited an unreported and peculiar behavior. Their concentrations consistently dropped in the middle of the tests but recovered toward the end, which suggest a complex effect of denitrifying conditions on aromatic amines. The transformation products NitroDiclofenac and 4-Nitro-Sulfamethoxazole were detected in the biotic experiments, while nitrite was present in the water. Their concentrations developed almost opposite to those of their respective parent compounds. We conjecture that this temporal and reversible effect of denitrifying conditions on the studied aromatic amines could have significant environmental implications, and could explain at least partially the wide range of removals in subsurface environments reported in literature for DCF and SMX, as well as some apparent discrepancies on SMX behavior.
\end{abstract}

(c) 2012 Elsevier B.V. All rights reserved.

\section{Introduction}

The last two decades have witnessed the ubiquitous emergence of pharmaceuticals in environmental matrices, i.e. surface water, ground water, soils and sediments (Focazio et al., 2008; Kemper, 2008; Loos et al., 2009; Petrovic et al., 2004 and references therein). An important source of these organic compounds is the discharge of effluents from wastewater treatment plants into surface water bodies (Gros et al., 2010; Onesios et al., 2009; Petrovic et al., 2009 and references therein). They also come from solid waste disposal, spills and uncontrolled discharges from industries, spreading of manure and sewage sludge as organic fertilizer in agricultural soils, surface run-off, etc. Their concentrations are usually in the ng/L to $\mu \mathrm{g} / \mathrm{L}$ range. Still, they are a cause of concern because of their potential chronic effects and synergic action of their mixtures on aquatic life and human health (Fent et al., 2006; Farré et al., 2008; Kumar et al., 2010).

\footnotetext{
* Corresponding author. Tel.: + 34 934006100x1640.

E-mail address: manuela.barbieri1@gmail.com (M. Barbieri).
}

As a result of this concern, significant efforts are being devoted to understanding the fate of pharmaceuticals in natural environments (Benotti and Brownawell, 2009; Holm et al., 1995; Hua et al., 2003; Yamamoto et al., 2009 and references therein). In this respect, intensive work is associated to managed aquifer recharge (Díaz-Cruz and Barceló, 2008 and ref. therein; Hoppe-Jones et al., 2010 and ref. therein; Patterson et al., 2009). Soil-aquifer processes have demonstrated to work as a natural treatment for the attenuation or complete removal of numerous contaminants, and the predominant redox conditions have proven to be an important controlling factor (Christensen et al., 2001). Nevertheless, knowledge on the behavior of drugs in the subsurface, their degradation pathways and the potential formation of transformation products is still limited.

This work is motivated by artificial recharge of groundwater practices using Llobregat river water (Barcelona area, Spain). We have carried out microcosm experiments involving natural aquifer material to investigate the fate of selected organic pollutants, mainly pharmaceuticals, under nitrate reducing conditions, which we expect will develop under recharge basins. We present in this paper the unreported and peculiar behavior exhibited during the experiments 
by two of the studied compounds, diclofenac and sulfamethoxazole. Their concentrations consistently dropped in the middle of the tests, but recovered toward the end.

Diclofenac (from now on DCF) is an important non-steroidal drug (NSAID) with anti-inflammatory, analgesic and antipyretic effects that is widely used for treatment of rheumatic diseases and for mild to moderate pain relief. Sulfamethoxazole (SMX) is a sulfonamide bacteriostatic antibiotic extensively used in both veterinary and human medicine. Both compounds are included as Class 1: high priority pharmaceuticals in the common list of pharmaceuticals relevant to the water cycle prepared by The Global Water Research Coalition (GWRC, 2004). Their physicochemical characteristics are reported in Table 1. Recent monitorings reported the occurrence of these two drugs in the Llobregat river basin at concentrations in the ng/L range (Köck-Schulmeyer et al., 2011; López-Roldán et al., 2010), with punctual maxima of some $\mu \mathrm{g} / \mathrm{L}$ (Muñoz et al., 2009). The existing literature on their fate in subsurface environments describes sorption onto aquifer material to be not significant at $\mathrm{pH}$ ranging between 7 and 8.3 (Baumgarten et al., 2011; Rauch-Williams et al., 2010). Field and laboratory studies on managed aquifer recharge (Heberer and Adam, 2004; Preuss et al., 2001; Rauch-Williams et al., 2010, and references therein; Scheytt et al., 2007; Ternes et al., 2007; Tiehm et al., 2010), covering a wide range of retention times and experiment duration, reported DCF to be quite efficiently eliminated under both aerobic (reported removals from $60 \%$ to $100 \%$ ) and anaerobic conditions (removals from $40 \%$ to $70 \%$ ). Regarding SMX, however, mixed and sometimes contradictory results have been reported on its fate in different natural systems. For example, investigations on soil-
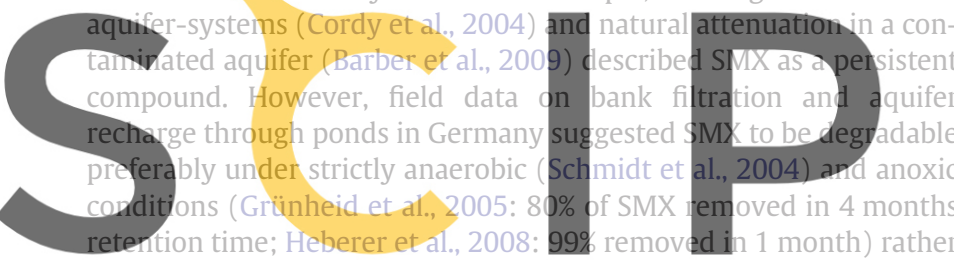

than under aerobic ones (Grünheid et al., 2005: 53\% removed in 50 days: Heberer et al. 2008: 52\% removed in 1 month). Finally, in

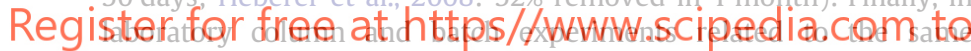
recharge sites, the largest removals of SMX were obtained under aerobic conditions, ranging between 23\% and 95\% (depending on the experimental settings and duration), whereas those under comparable anoxic conditions varied between 0\% and 65\% (Baumgarten et al., 2011; Jekel et al., 2009).

We conjecture that the wide range of reported removals for DCF and SMX as well as the apparent discrepancies in the literature on
SMX behavior could be explained, at least partially, by a transient and reversible effect of denitrifying conditions on aromatic amines.

\section{Materials and methods}

The experiments consisted of sets of microcosms containing natural sediments, synthetic water and organic pollutants. The latter were spiked at individual concentrations of $1 \mu \mathrm{g} / \mathrm{L}$, i.e. environmental concentrations, in "Experim. $1 \mu \mathrm{g} / \mathrm{L}$ ". To check the representativeness of studies at concentrations easier to be tested and analyzed, a markedly higher individual concentration of $1 \mathrm{mg} / \mathrm{L}$ was used for pollutants in "Experim. $1 \mathrm{mg} / \mathrm{L}$ ". Both experiments included a biotic and an abiotic series to separate contaminant's biodegradation (both biotic mineralization and transformation included here) from sorption and other abiotic processes. Nitrate reducing conditions were stimulated in the biotic tests by adding easily degradable organic compounds as electron donors (sodium acetate and the methanol used as solvent in the pollutants' spiking solutions) and an excess of nitrate as specific electron accentor. A more exhaustive descrintion of the experimental design and methodology as well as details on the complete set of the organic pollutants included in the experiments could be found in Barbieri et al. (2011) and references therein.

\subsection{Organic pollutants}

DCF and SMX (purity $>96 \%$ ), diclofenac- $d 4$, sulfamethoxazole- $d 4$ and ibuprofen- $d 3$ were purchased from Sigma Aldrich. SMX $-{ }^{13} C_{6}$ was supplied by LGC Promochem. Nitro-Diclofenac (from now on
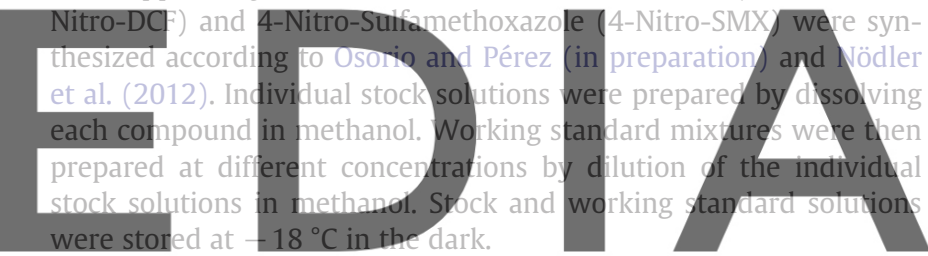

\subsection{Sediments and water}

\section{download the version without the watermark}

Sediments were obtained from a test site for artificial recharge of groundwater through surface ponds located in Sant Vicenç dels Horts (Barcelona, Spain). The aquifer consists of quaternary alluvial sediments, mainly gravel and sand with a small fraction of clays. Samples were collected before any artificial recharge activities, from an oxic unsaturated horizon at about $1 \mathrm{~m}$ below the infiltration pond. They were sieved to $<1 \mathrm{~mm}$ and immediately used for assembling

Table 1

Physicochemical properties of the compounds of interest.

\begin{tabular}{|c|c|c|c|c|c|}
\hline Compound & Structure & CAS number & $\log \mathrm{K}_{\mathrm{ow}}^{\mathrm{a}, \mathrm{b}}$ & $\mathrm{pk}_{\mathrm{a}}{ }^{\mathrm{a}}$ & Formula \\
\hline Diclofenac (DCF) & & $15307-86-5$ & $4.06 \pm 0.41$ & $4.2 \pm 0.1$ & $\mathrm{C}_{14} \mathrm{H}_{10} \mathrm{Cl}_{2} \mathrm{NO}_{2}$ \\
\hline Sulfamethoxazole (SMX) & & $723-46-6$ & $0.89 \pm 0.42$ & $\begin{array}{l}5.8 \pm 0.5^{\mathrm{c}} \\
1.4 \pm 0.1^{\mathrm{d}}\end{array}$ & $\mathrm{C}_{10} \mathrm{H}_{11} \mathrm{~N}_{3} \mathrm{O}_{3} \mathrm{~S}$ \\
\hline
\end{tabular}

\footnotetext{
a SciFinder predicted values.

b $\log K_{\mathrm{OW}}$ value of the neutral species.

c pKa value of the secondary amine.

d Basic pKa value of the primary amine (pKa of the conjugate acid).
} 
the experiments, or stored before use for a maximum of two days at $25{ }^{\circ} \mathrm{C}$ inside aluminum foil. Their mineralogical and chemical characteristics are summarized in Table S1 of the Supporting Information.

The experiment water was artificially prepared to mimic recharge water (Llobregat river water) at test site except for the organic carbon, which was initially zero. This water was prepared in a glass amber bottle by dissolving respective amounts of salts (sodium bicarbonate, sodium sulfate, sodium chloride, calcium chloride dihydrate, magnesium nitrate hexahydrate, potassium chloride, magnesium chloride hexahydrate, potassium dihydrogen phosphate and ammonium chloride). All salts were purchased from Sigma Aldrich in ultrapure water. Its composition is shown in Table S2 of the Supporting Information. Nitrate concentration was then increased by further dissolution of magnesium nitrate hexahydrate (additional $7.3 \mathrm{mmol} / \mathrm{L}$ and $66 \mathrm{mmol} / \mathrm{L}$ of nitrate for the waters of "Experim. $1 \mu \mathrm{g} / \mathrm{L}$ " and "Experim. $1 \mathrm{mg} / \mathrm{L}$ ", respectively). Finally, the water was purged with Ar (purity $\geq 99.999 \%$ ) for about $1 \mathrm{~h}$ to remove all oxygen from the solution and the bottle headspace.

\subsection{Experimental procedure}

The sediments were homogenized in steel containers and distributed in fractions of $120 \mathrm{~g}$ (dry weight) into $0.3 \mathrm{~L}$ glass bottles. The $0.3 \mathrm{~L}$ bottles as well as the glass amber bottle containing the previously prepared water (Section 2.2) were then placed inside a glove box under Argon atmosphere (maximum $0.1 \%$ of $\mathrm{O}_{2}$ ). $2.1 \mathrm{mmol} / \mathrm{L}$ of anhydrous sodium acetate was added to the synthetic water. Afterwards, the organic pollutants were also added to the water from their meth-

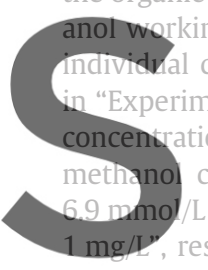
ing standard mixtures (Section
concentrations of $1 \mu \mathrm{g} / \mathrm{L}$ in "Ex
$\mathrm{m}$. $1 \mathrm{mg} / \mathrm{L}$ ". The expected Dissol
con resulting from the additi
$\mathrm{L}$ and $80 \mathrm{mmol} / \mathrm{L}$ for "Experi
espectively. After measuring pa
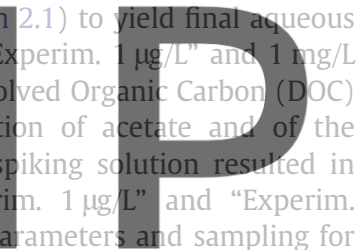

chemical analysis, $0.24 \mathrm{~L}$ of the initial water obtained was then added to each $0.3 \mathrm{~L}$ glass bottle already containing the sediments.

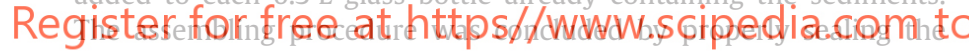

bottles against oxygen with screw-caps plus a PTFE protection seal, and gently shaking. A remaining headspace of about $15 \mathrm{~mL}$ was left in each bottle.

The microcosms were removed from the glove box and wrapped with aluminum foil to prevent photodegradation. Then, they were incubated under controlled temperature $\left(25 \pm 2{ }^{\circ} \mathrm{C}\right)$ and gently shaken a few times during their lifetime (once every 2 days during the first week; once a week during the rest of the first month; then, once every 30 days) as well as the day before dismantlement.

For the abiotic series, synthetic water and sediments were sterilized prior to assembling. They were introduced three times (once a day in three consecutive days) into an autoclave at $\mathrm{T}=121{ }^{\circ} \mathrm{C}$ and $\mathrm{P}=$ Patm $+1 \mathrm{~atm}$ for $20 \mathrm{~min}$. The glove box was sterilized with UV light before entering the material. As an additional precaution, $0.22 \mathrm{mmol} / \mathrm{L}$ of mercury chloride was added as microbial poison to the initial water.

Duplicate bottles were sacrificed according to pre-defined schedules (at days $0.05,0.2,0.5,1.5,3,5,10$ and 21 for "Experim. $1 \mu \mathrm{g} / \mathrm{L}$ "; at days 2, 5, 10, 15, 25, 41 and 87 for "Experim. $1 \mathrm{mg} / \mathrm{L}$ "). One at a time, the two bottles were opened under Ar atmosphere, chemical parameters were measured, and aqueous samples for bulk chemistry and pollutants analysis were collected and stored as described in Section 2.4 until analysis. Sterility of the abiotic series was verified six times in "Experim. $1 \mu \mathrm{g} / \mathrm{L}$ " series and twice in "Experim. $1 \mathrm{mg} / \mathrm{L}$ " series. To this end, an aliquot of microcosms water was spread on tryptic soy agar (TSA) plates and incubated in duplicate at $25^{\circ} \mathrm{C}$ for 1 week under aerobic conditions and for 2 weeks under anaerobic conditions. None of the plates demonstrated microorganisms' growth.

\subsection{Analytical methods}

\subsubsection{Bulk water chemistry analysis}

Biotic samples collected during microcosms' assembling/ disassembling for the analysis of $\mathrm{Cl}^{-}, \mathrm{NO}_{3}^{-}, \mathrm{NO}_{2}^{-}, \mathrm{SO}_{4}^{2-}, \mathrm{PO}_{4}^{3-}, \mathrm{F}^{-}$, $\mathrm{NH}_{4}^{+}$and DOC (Dissolved Organic Carbon) were filtered through $0.45 \mu \mathrm{m}$ PALL Acrodisc ${ }^{\circledR}$ Sterile Syringe Filters with Supor ${ }^{\circledR}$ membrane and frozen. Anions were analyzed by ion chromatography using a Dionex ICS-1000 instrument. The analytical error was estimated to be $14 \%$ for $\mathrm{PO}_{4}^{3-}$ and $13 \%$ for the remaining anions. Detection limits for $\mathrm{NO}_{3}^{-}$and $\mathrm{NO}_{2}^{-}$were $0.5 \mathrm{mg} / \mathrm{L}$ and $0.05 \mathrm{mg} / \mathrm{L}$, respectively. $\mathrm{NH}_{4}^{+}$concentration was analyzed with a selective electrode Orion 9512. Its detection limit was $0.1 \mathrm{mg} / \mathrm{L}$. DOC was analyzed by $680{ }^{\circ} \mathrm{C}$ combustion catalytic oxidation/NDIR method using a Shimadzu TOC-V CSH instrument. The estimated analytical error was $20 \%$. Biotic and abiotic samples for analyzing COD (Chemical Oxygen Demand) were also filtered $0.45 \mu \mathrm{m}$ and frozen, to be further on analyzed by colorimetry with the spectrophotometer Spectroquant Nova 60. Abiotic samples for $\mathrm{Cl}^{-}, \mathrm{NO}_{3}^{-}, \mathrm{SO}_{4}^{2-}$ and $\mathrm{F}^{-}$were frozen and then analyzed by ion chromatography using a Dionex DX-320 instrument with conductometric detection, a Dionex AS11-HC $(2 \times 250 \mathrm{~mm})$ column and $23 \mathrm{mM} \mathrm{KOH}$ as eluent (isocratic separation at $30{ }^{\circ} \mathrm{C}$ ). A flow rate of $0.38 \mathrm{~mL} \mathrm{~min}^{-1}$ was applied. Prior to chromatography, samples were filtered (Whatman Anotop 10 IC, $0.2 \mu \mathrm{m}$ ). The analytical error was estimated to be $8 \%$.

Samples for $\mathrm{Ca}, \mathrm{Mg}, \mathrm{Na}, \mathrm{K}$ and minor elements were filtered at $0.45 \mu \mathrm{m}$, acidified and stored at $4{ }^{\circ} \mathrm{C}$. They were later analyzed by inductively coupled plasma atomic emission spectrometry (ICP-AES)

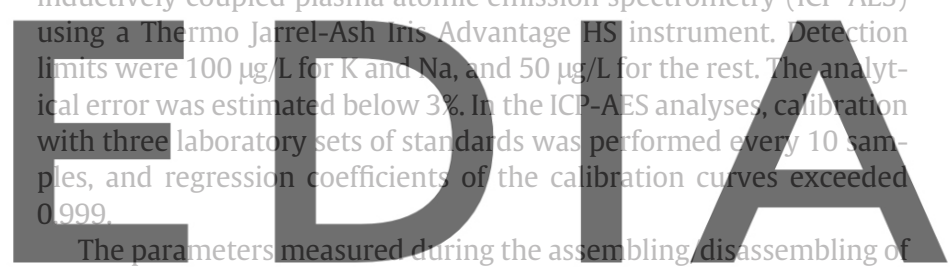
the microcosms were: pH (Thermo Scientific 9157BN Triode pH electrode, refillable), dissolved oxygen (Hanna Instruments, HI 76407/4

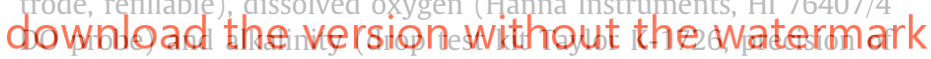
$0.5 \mathrm{mmol} / \mathrm{L}$ ).

\subsubsection{Micropollutants analysis in "Experim. $1 \mu \mathrm{g} / \mathrm{L}$ "}

The aqueous calibration standards for DCF and SMX (concentration range 1-1500 $\mathrm{ng} / \mathrm{L}$ ) were prepared by using the methanol working standard mixtures described in Section 2.1. Diclofenac-d4 and sulfamethoxazole- $d 4$ were used as surrogate standards for DCF and SMX quantification, respectively. The surrogate standard mixture in methanol was also prepared according to the procedure described in Section 2.1, and then added to the water samples from the experiment and to the aqueous calibration standards just before analysis to yield final concentration of $200 \mathrm{ng} / \mathrm{L}$.

Samples collected during microcosms' assembling/disassembling for analysis of organic pollutants were filtered at $0.45 \mu \mathrm{m}$ using WATERS Syringe filter with PTFE membrane and frozen. Their analysis was then performed by on-line solid phase extraction-liquid chromatography-tandem mass spectrometry (SPE-LC-MS/MS). Briefly, water samples and all the aqueous calibration standards, spiked with the standard mixture of the isotopically labeled compounds at a concentration of $200 \mathrm{ng} / \mathrm{L}$, were extracted with the aid of an automated on-line SPE sample processor Prospekt-2 from Spark Holland (Emmen, The Netherlands) connected in series with the LC-MS/MS instrument. The main advantage of the method is that aqueous calibration and surrogates standards are processed in the same way as samples. Sample and calibration standards preconcentration were performed by passing $5 \mathrm{~mL}$ of the sample through a previously conditioned ( $1 \mathrm{~mL}$ methanol plus $1 \mathrm{~mL}$ HPLC water) Oasis HLB Prospekt ${ }^{\mathrm{TM}}$ cartridge $(10 \times 1 \mathrm{~mm})$ from Waters (Mildford, MA, USA). After sample 
loading, the cartridge was washed with $1 \mathrm{~mL}$ of a $5 \%$ methanol water solution and further eluted with the chromatographic mobile phase. Chromatographic separation was performed with a binary HPLC pump Model 1525 from Waters using a Purospher STAR RP-18e column $(125 \times 2 \mathrm{~mm}, 5 \mathrm{~m}$ particle diameter, from Merck, Darmstadt, Germany) and gradient elution with methanol and water as mobile phase. MS/MS detection was performed in the selected reaction monitoring (SRM) mode acquiring 2 SRM transitions per compound and 1 SRM transition per surrogate (see experimental conditions in Table S3 of the Supporting Information) using a TQD triplequadrupole mass spectrometer from waters equipped with an electrospray interface. Quantitation was performed by the internal standard method using the corresponding deuterated compounds as surrogate standards.

The analytical method developed showed good validation parameters in terms of accuracy (relative recovery - comparison of the absolute recoveries of the analytes with those of their surrogates between $106.7 \%$ and $108.3 \%$ ) and repeatability (RSD $<25 \%)$. The validation was carried out with a fivefold study $(n=5)$ and synthetic water with an initial concentration of the analytes of $1 \mu \mathrm{g} / \mathrm{L}$. The main advantage of the developed method is its improved accuracy due to the use of the isotope dilution method.

\section{Pollutants analysis in "Experim. $1 \mathrm{mg} / \mathrm{L}$ "}

For the quantification of DCF and SMX, the internal standards $100 \mathrm{ng} / \mathrm{mL}$ ibuprofen-d3 and $125 \mathrm{ng} / \mathrm{mL} \mathrm{SMX}-{ }^{13} \mathrm{C}_{6}$ were used, respectively. The suitability of ibuprofen- $\mathrm{d}_{3}$ for the quantification of DCF was demonstrated previously (Nödler et al., 2010). Calibration

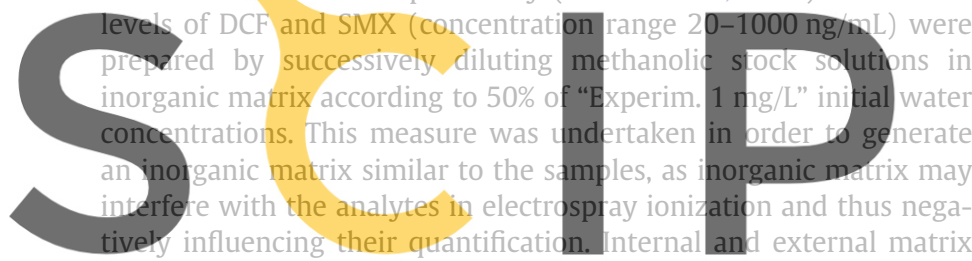
adjusted calibration ensured data quality. The overall Relative Standard Deviation (RSD) of multiple injections was $<5 \%$ for all analyses.

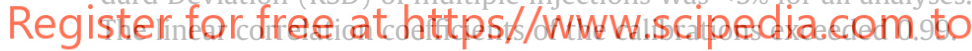

Samples collected during microcosms' assembling/disassembling for analysis of organic pollutants were kept frozen until analysis. Prior to DCF and SMX analysis, samples and calibration levels were diluted (v/v) 1:2 (DCF) and 1:4 (SMX) with aqueous $5 \mathrm{mM}$ ammonium acetate solution, containing 4\% methanol. Before analysis, all samples and calibration levels were centrifuged at $1500 \mathrm{rpm}$ for $30 \mathrm{~min}$ at room temperature. Analysis of DCF was performed without preconcentration by an HPLC/MS-MS method according to Nödler et al., 2010. SMX analysis was performed by using the same instrumentation and eluents. However, the gradient was slightly different. Eluent A was $0.015 \%$ formic acid $+5 \%$ methanol. The elution started with $5 \%$ B (methanol) followed by a gradient of $27 \mathrm{~min}$ to $65 \% \mathrm{~B}$. This was followed by a sharp gradient of $1 \mathrm{~min}$ to $95 \% \mathrm{~B}$, which was held for $5 \mathrm{~min}$. After a gradient of $1 \mathrm{~min}$ to $5 \%$ B the system was allowed to equilibrate for $11 \mathrm{~min}$. The parameters of the mass spectrometer for DCF and SMX analysis are provided in Table S4 of the Supporting Information.

\section{Results and discussion}

Results are presented below in terms of averages of data from the duplicate batches. Namely, the temporal evolution of the organic pollutants is reported in terms of their average concentration divided by the corresponding initial concentration $C_{0}$. The objective of this normalization is to remove systematic errors from the analyses.

The error bars reported in the figures have been calculated by considering the analytical errors and the difference between batches results (details are given in Text S2 of the Supporting Information).
Regarding the abiotic tests, water chemistry remained as expected practically constant for the whole time (results not shown).

\subsection{Bulk water chemistry}

The evolution of water chemistry in the biotic series of "Experim. $1 \mu \mathrm{g} / \mathrm{L}$ " (pollutants at $1 \mu \mathrm{g} / \mathrm{L}$ individual initial concentration) is shown in Fig. 1a. During the first 10 days, DOC decreased from $9.7 \mathrm{mmol} / \mathrm{L}$ to $1.5 \mathrm{mmol} / \mathrm{L}$ while alkalinity increased from $1 \mathrm{mmol} / \mathrm{L}$ to $3.75 \mathrm{mmol} / \mathrm{L}$. Afterwards, both remained practically constant. No oxygen was detected during the whole experiment. By day 10 , the initial $6.7 \mathrm{mmol} / \mathrm{L}$ of nitrate had disappeared. Nitrite concentration began to increase after some $12 \mathrm{~h}$, reaching a maximum at day 5 and becoming depleted by day 10 . Very low concentrations of dissolved manganese and iron were detected after day 10 (results not shown), presumably from the dissolution and reduction of small quantities of the Mn and Fe oxides naturally present in the sediments. Sulfate remained constant and $\mathrm{pH}$ decreased with slight fluctuations from 8.5 to 7.7 during the whole experiment.

These observations suggest that nitrate reducing conditions were established after a short period ( 0.5 days) of microbial adaptation and dominated the system during the first 10 days, while nitrate remained in the system. The increase of nitrite, followed by its depletion, reflects the actual denitrification pathway, with nitrite being an intermediate product between nitrate and nitrogen. More reducing conditions were established after nitrate and nitrite were exhausted, as suggested by the slight increase of $\mathrm{Mn}$ and Fe.

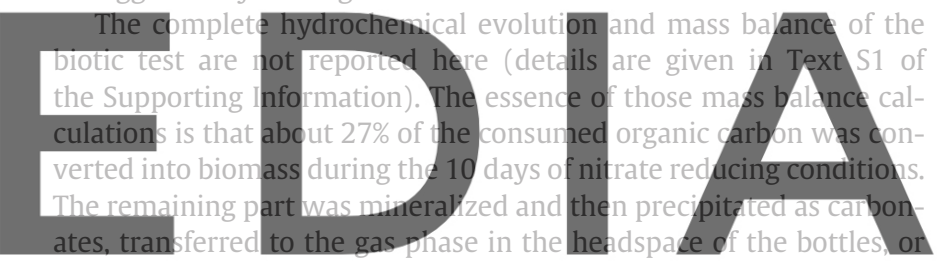

remained in solution to increase alkalinity. Under these assumptions, the overall inorganic carbon mass balance could be closed with an dawaboaditthe version without the watermark

Results for the water chemistry of the biotic series of "Experim. $1 \mathrm{mg} / \mathrm{L}$ " (pollutants at $1 \mathrm{mg} / \mathrm{L}$ individual initial concentration) are shown in Fig. 1b. Qualitatively, its evolution is consistent with that of the biotic series of "Experim. $1 \mu \mathrm{g} / \mathrm{L}$ " though displaced in the time scale. DOC and nitrate decreased throughout the experiment, starting (appreciably) after day 5 but still remaining by day 87 with final concentrations of $27.2 \mathrm{mmol} / \mathrm{L}$ and $7.5 \mathrm{mmol} / \mathrm{L}$, respectively. Alkalinity increased continuously from $0.8 \mathrm{mmol} / \mathrm{L}$ to $22 \mathrm{mmol} / \mathrm{L}$ starting at day 2. Nitrite concentrations also began to increase at day 2, reaching a maximum at day 41 , and becoming depleted at day 87 . Dissolved oxygen, manganese and iron were not detected, sulfate remained constant, and $\mathrm{pH}$ ranged between 7.3 and 8.3 during the experiment.

The above observations suggest that nitrate reducing conditions were established within approximately 2 days of microbial adaptation, and dominated the system during the rest of the test. The somehow longer adaptation time of microbial communities, compared to that characterizing "Experim. $1 \mu \mathrm{g} / \mathrm{L}$ ", could be likely related to the different proportion of methanol present in "Experim. $1 \mathrm{mg} / \mathrm{L}$ " or possibly to some growth inhibition by SMX (Underwood et al., 2011). The practical depletion of nitrite between days 41 and 87, when nitrate reduction was still occurring, can be attributed to nitrite reduction to nitrogen being faster than the production of nitrite from nitrate during such period.

In this case, about $5 \%$ to $10 \%$ of the organic carbon was calculated to be converted into biomass. Accounting for carbonates precipitation, transfer to the headspace of the bottles, and alkalinity build up, the overall inorganic carbon mass balance could be closed with an error of about $10 \%$. 

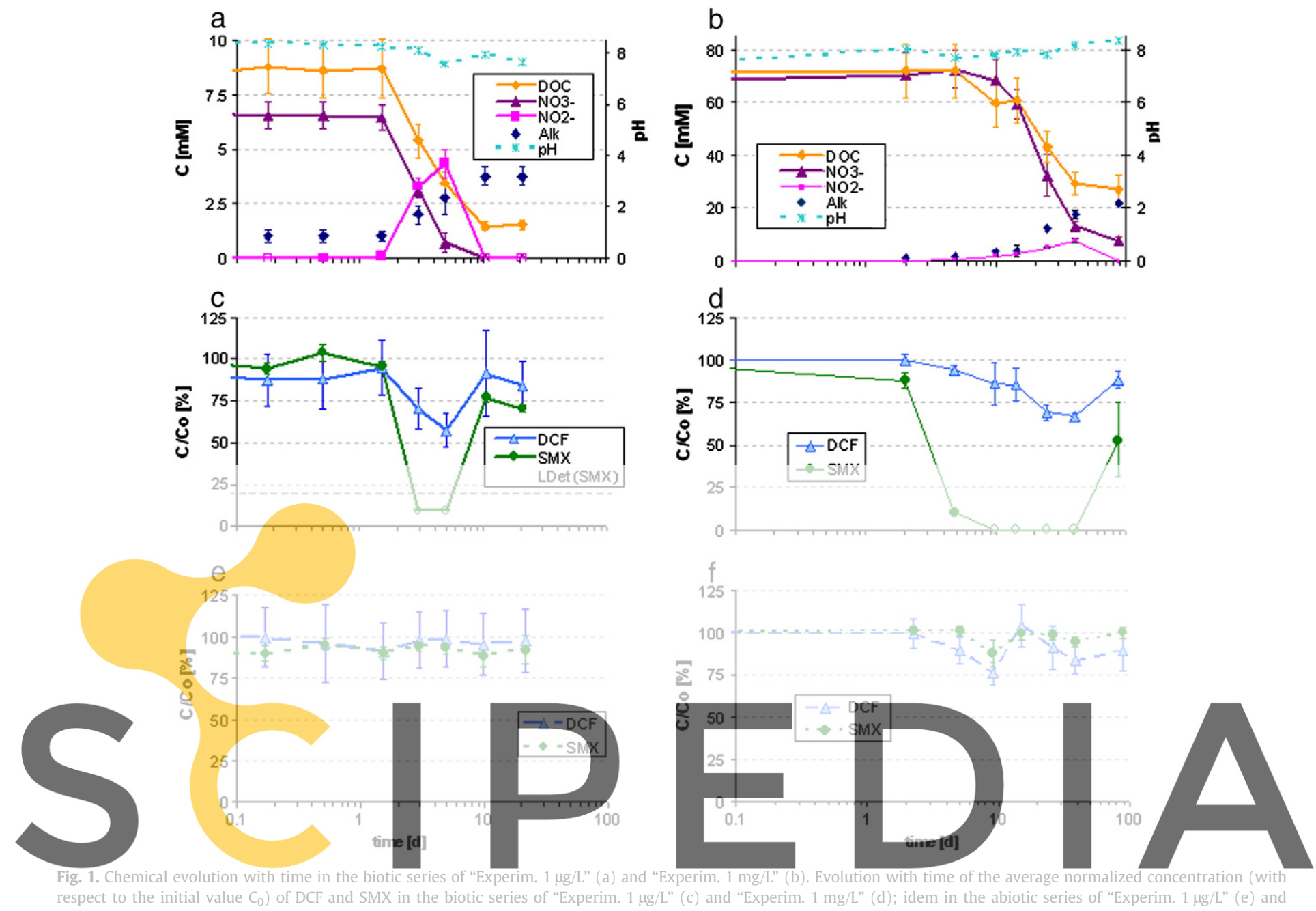

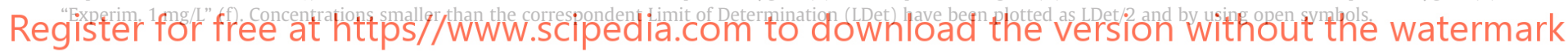

\subsection{Organic pollutants}

The time evolutions of DCF and SMX in the biotic and abiotic series of "Experim. $1 \mu \mathrm{g} / \mathrm{L}$ " (pollutants at $1 \mu \mathrm{g} / \mathrm{L}$ individual initial concentration) and "Experim. $1 \mathrm{mg} / \mathrm{L}$ " (pollutants at $1 \mathrm{mg} / \mathrm{L}$ individual initial concentration) are reported in Fig. 1c, e, d and f, respectively. Both compounds were negatively charged within the $\mathrm{pH}$ range of the experiments.

Overall, DCF was not removed in "Experim. $1 \mu \mathrm{g} / \mathrm{L}$ " after 10 days of nitrate reducing conditions. Its final normalized concentration in both biotic and abiotic series (Fig. 1c and e) remained around 100\% (considering the error bars). Nevertheless, its concentration in the biotic series suffered a sudden drop at day 1.5 , followed by complete recovery by day 10 .

An analogous pattern could be observed for DCF in "Experim. $1 \mathrm{mg} / \mathrm{L}$ " (Fig. 1d and f), but displaced in the time scale. On the whole, DCF was not or only slightly (10\%) removed during the 87 days of both biotic and abiotic tests. But its concentration in the biotic set of microcosms also suffered a drop between day 2 and day 41 followed by a recovery between days 41 and 87 .

The overall removal of SMX was about 25\% during the 10 days of nitrate reducing conditions in the biotic series of "Experim. $1 \mu \mathrm{g} / \mathrm{L}$ " (Fig. 1c), and $47 \pm 20 \%$ after 87 of nitrate reducing conditions in the biotic series of "Experim. $1 \mathrm{mg} / \mathrm{L}$ " (Fig. 1d). But SMX concentration also dropped, even more sharply than DCF (down to near zero concentration), between days 1.5 and 10 of the biotic test of "Experim. $1 \mu \mathrm{g} / \mathrm{L}$ ", rebounding afterwards. Again, the same non-monotonic behavior but displaced in the time scale could be observed for SMX in the biotic test of "Experim. $1 \mathrm{mg} / \mathrm{L}$ ". As for DCF in "Experim. $1 \mathrm{mg} / \mathrm{L}$ ", the SMX drop and recovery occurred between days 2 and 87. In the abiotic series of both tests (Fig. 1e and f), on the other hand, SMX concentrations remained constant all time long.

The evolution of the two pharmaceuticals and the bulk water chemistry (Fig. 1) shows that such unexpected reversible process of drop and rebound of both DCF and SMX concentrations occurs only in the biotic series, concurrently and opposite to the evolution of nitrite. Among all the organic pollutants included in the experiments (results not shown), such peculiar trend could be observed only for DCF and SMX, which were the only aromatic amines in the tests.

\subsection{Discussion upon the effect of denitrifying conditions on DCF and SMX}

A further analysis of the water samples exhibited the presence of additional peaks emerging in the chromatograms after day 0.5 and after day 2 in the biotic series of "Experim. $1 \mu \mathrm{g} / \mathrm{L}$ " and "Experim. $1 \mathrm{mg} / \mathrm{L}$ ", respectively, representing possible candidates for DCF and SMX transformation products. Based on ongoing studies and previous literature (Nödler et al., 2012; Osorio and Pérez, in preparation; Pérez and Barceló, 2008), two of the newly emerging peaks suggested nitro analogs of DCF and SMX. Indeed, among them we could detect the presence of Nitro-DCF and 4-Nitro-SMX with authentic standards (Section 2.1). Multiple injections resulted in a RSD of $20 \%$. The 
Table 2

Physicochemical properties of the transformation products Nitro-DCF and 4-Nitro-SMX detected in the biotic series.

\begin{tabular}{|c|c|c|c|c|}
\hline Compound & Structure & CAS number & $\log K_{o w}{ }^{a}$ & $\mathrm{pk}_{\mathrm{a}}$ \\
\hline Nitro-Diclofenac $\left(\mathrm{NO}_{2}\right.$-DCF) & & $174316-61-1$ & $4.86^{\mathrm{b}}$ & $3.82^{\mathrm{b}}$ \\
\hline 4-Nitro-Sulfamethoxazole (4- $\left.\mathrm{NO}_{2}-\mathrm{SMX}\right)$ & & 29699-89-6 & $1.27 \pm 0.41^{\mathrm{c}}$ & $5.65 \pm 0.4^{\mathrm{c}}$ \\
\hline
\end{tabular}

a $\log K_{\text {ow }}$ value of the neutral species.

b SPARC predicted values for 3-NO2-DCF (http://archemcalc.com/sparc).

c SciFinder predicted values.

characteristics and structures of the two compounds, being anionic within the pH range of our experiments, are reported in Table 2.

As presented in Fig. 2, the evolution of both Nitro-DCF and 4Nitro-SMX concentrations developed almost opposite to that of their respective parent compounds, and matches very well that of nitrite. As such, their concentration increases with nitrite, while that of their parent compounds decreases. Furthermore, the two nitro derivatives become completely depleted at the same time as nitrite, which coincides with the rebound of the parent

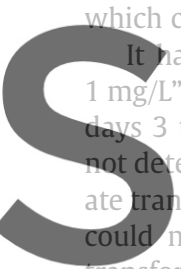

has to be noted that in both

" the concentration of 4-Nitrd-si 3 to 5 and from days 10 to 25

ansformation product of SMX to 4 neither identify such possible int

inedrate nor further DCF

SIMX fate. In spite of these restraints, it is important to stress that the trends observed for both drugs and their respective nitro derivatives could be confirmed in experiments testing two markedly different initial concentrations of DCF and SMX (i.e., $1 \mu \mathrm{g} / \mathrm{L}$ to $1 \mathrm{mg} / \mathrm{L}$ ), and characterized by a different evolution of denitrification in the time scale (Section 3.1).

The presented findings suggest thus a reversible nature of NitroDCF and 4-Nitro-SMX formation. In summary, even if the specific mechanisms are still unclear, we propose that the drop in concentra-

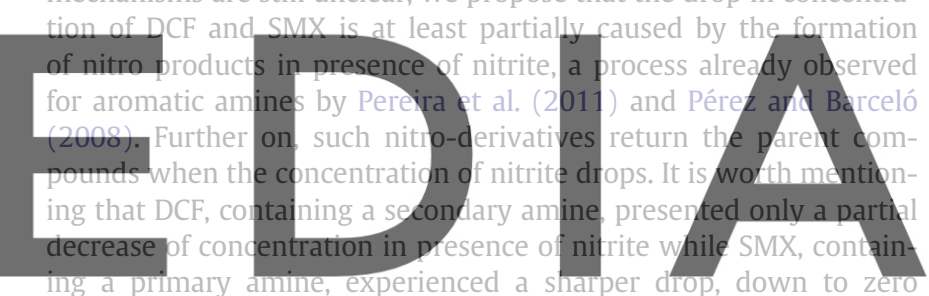
concentration.

Register for free at https//www.scipedia.com to download the version without the watermark
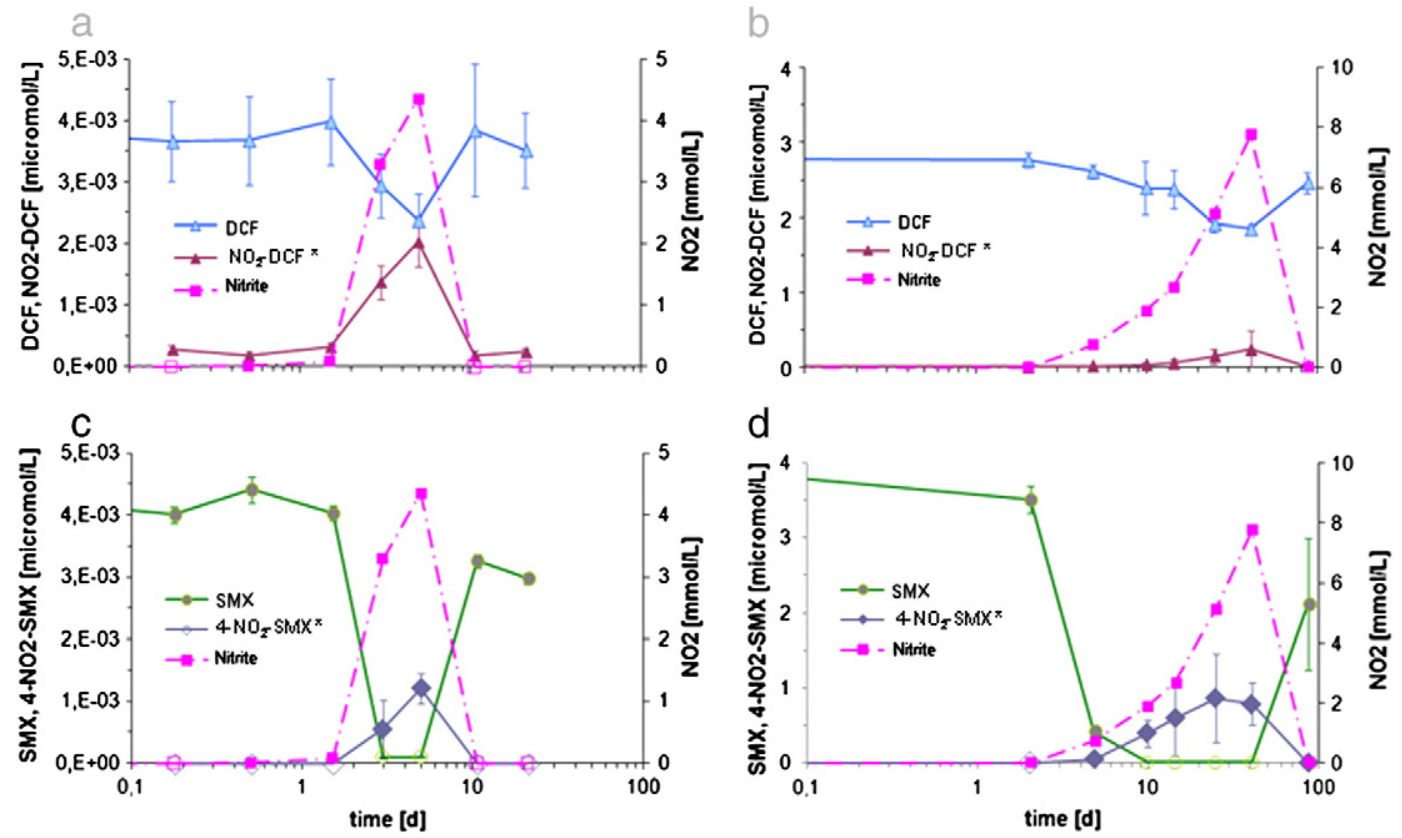

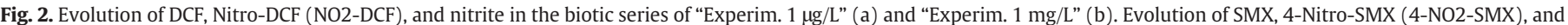

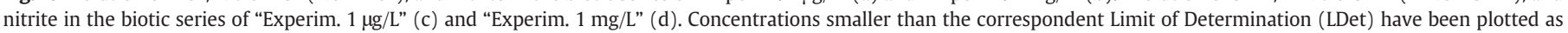

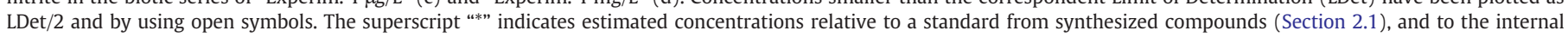
standards used for quantification of the parent compounds. 


\section{Implications}

- We have observed that the fate in aquifer material of the aromatic amines diclofenac and sulfamethoxazole could be temporarily and reversibly affected by denitrifying conditions. Namely, the concentration of these two drugs decreases when nitrite builds up, but rebounds when nitrite is reduced toward nitrogen.

- Nitro-DCF and 4-Nitro-SMX, transformation products of DCF and SMX, were detected. The concentration of the two nitro-derivatives developed almost complementary to the measured decrease in the concentrations of their parent compounds, and correlated very well with the temporal evolution of the nitrite peak.

- DCF, containing a secondary amine, presented only a partial decrease of concentration while SMX, containing a primary amine, experienced a drop down to zero concentration. The specific mechanisms of these reactions are still unclear, but nitrite could be likely involved/responsible of the formation of the two detected nitro compounds from the studied aromatic amines.

There could be a significant environmental implication of the presented findings related to the fate in aquifers under denitrifying conditions of DCF and SMX, and possibly other aromatic amines. Ignoring the observed transient drop of these compounds could lead experimenters to overestimate their actual elimination in field and laboratory studies. This may explain the wide ranges of removals reported for DCF and SMX, as well as the inconsistencies on literature reports about their elimination (e.g. in the case of SMX). This also

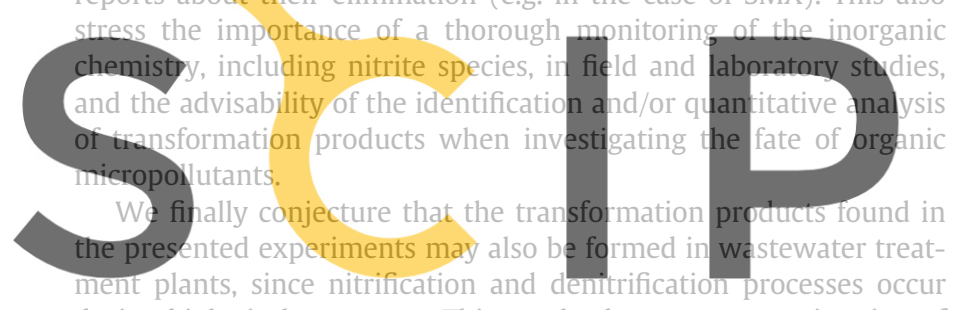
during biological treatment. This can lead to a wrong estimation of

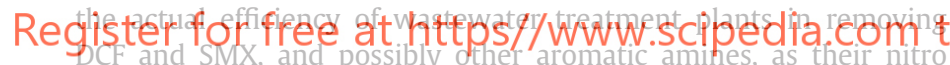
derivatives can transform back into the parent compounds when released in the environment.

Supplementary materials related to this article can be found online at doi:10.1016/j.scitotenv.2012.02.058.

\section{Acknowledgments}

This work has been supported by the European projects GABARDINE, DECRAT (R + I Alliance), ENSAT (LIFE08 ENV/E/117), and by the Spanish Ministry of Science and Innovation through the projects RARA AVIS (CGL2007-64551/HID), SCARCE (Consolider-Ingenio 2010 CSD2009-00065) and CEMAGUA (CGL2007-64551/HID). The following persons are gratefully acknowledged: Alicia Roig López, Anna Maria Solanas and her group (Dept. of Microbiology, UB), Albert Soler and his group (Dept. Crystallography and Mineralogy, UB). M.B. acknowledges AGAUR (Generalitat de Catalunya, Spain) for the economical support through a FI pre-doctoral grant. M.K. acknowledges the European Social Fund and AGAUR for their economical support through a FI pre-doctoral grant. SP acknowledges the contract from the Ramón y Cajal Program of the Spanish Ministry of Science and Innovation. Merck is acknowledged for the gift of LC columns.

\section{References}

Barber LB, Keefe SH, LeBlanc DR, Bradley PM, Chapelle FH, Meyer MT, et al. Fate of sulfamethoxazole, 4-nonylphenol, and 17beta-estradiol in groundwater contaminated by wastewater treatment plant effluent. Environ Sci Technol 2009;43(13): 4843-50.
Barbieri M, Carrera J, Sanchez-Vila X, Ayora C, Cama J, Köck-Schulmeyer M, et al. Microcosm experiments to control anaerobic redox conditions when studying the fate of organic micropollutants in aquifer material. J Contam Hydrol 2011;126:330-45.

Baumgarten B, Jährig J, Reemtsma T, Jekel M. Long term laboratory column experiments to simulate bank filtration: factors controlling removal of sulfamethoxazole. Water Res 2011;45(1):211-20.

Benotti MJ, Brownawell BJ. Microbial degradation of pharmaceuticals in estuarine and coastal seawater. Environ Pollut 2009;157(3):994-1002.

Christensen TH, Kjeldsen P, Bjerg P, Jensen D, Christensen JB, Baun A, et al. Biogeochemistry of landfill leachate plumes. Appl Geochem 2001;16(7):659-718.

Cordy GE, Duran NL, Bouwer H, Rice RC, Furlong ET, Zaugg SD, et al. Do pharmaceuticals, pathogens, and other organic waste water compounds persist when waste water is used for recharge? Ground Water Monit Rem 2004;24(2):58-69.

Díaz-Cruz MS, Barceló D. Trace organic chemicals contamination in ground water recharge. Chemosphere 2008;72(3):333-42.

Farré M, Pérez S, Kantiani L, Barceló D. Fate and toxicity of emerging pollutants, their metabolites and transformation products in the aquatic environment. TrAC Trends Anal Chem 2008;27(11):991-1007.

Fent K, Weston AA, Caminada D. Ecotoxicology of human pharmaceuticals. Aquat Toxicol 2006;76(2):122-59.

Focazio MJ, Kolpin DW, Barnes KK, Furlong ET, Meyer MT, Zaugg SD, et al. A national reconnaissance for pharmaceuticals and other organic wastewater contaminants in the United States - II. Untreated drinking water sources. Sci Total Environ 2008;402(2-3):201-16.

Gros M. Petrovic M. Ginebreda A, Barceló D. Removal of pharmaceuticals during waste water treatment and environmental risk assessment using hazard indexes. Environ Int 2010;36(1):15-26.

Grünheid S, Amy G, Jekel M. Removal of bulk dissolved organic carbon (DOC) and trace rganic compounds by bank filtration and artificial recharge. Water Res 2005;39(14): 3219-28.

GWRC. Pharmaceuticals and personal care products in the water cycle. An international review, London, UK: 2004

Heberer T, Adam M. Transport and attenuation of pharmaceutical residues during artificial groundwater replenishment. Environ Chem 2004(1):22-5.

Heberer T, Massmann G, Fanck B, Taute T, Dünnbier U. Behaviour and redox sensitivity of antimicrobial residues during bank filtration. Chemosphere 2008;73(4):451-60.

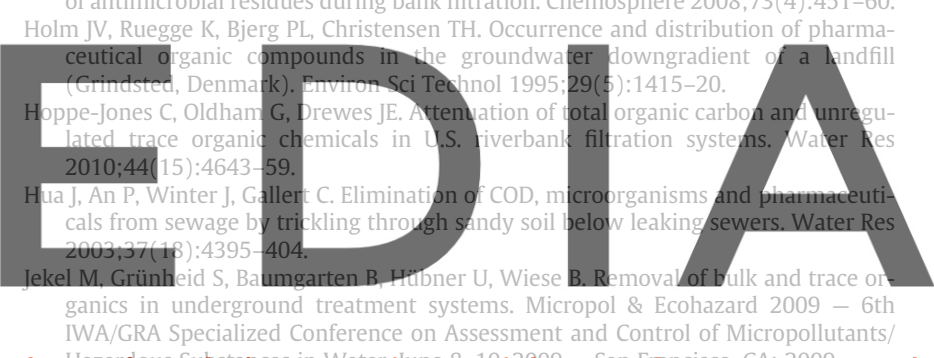

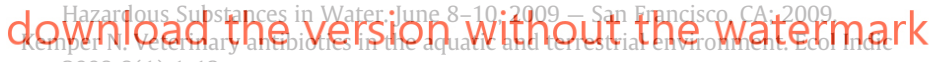

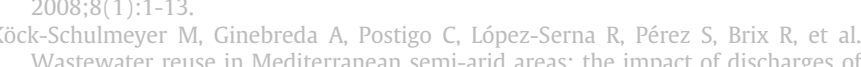
Wastewater reuse in Mediterranean semi-arid areas: the impact of discharges of tertiary treated sewage on the load of polar micro pollutants in the Llobregat river (NE Spain). Chemosphere 2011;82(5):670-8.

Kumar A, Chang B, Xagoraraki I. Human health risk assessment of pharmaceuticals in water: issues and challenges ahead. Int J Environ Res Public Health 2010;7(11): 3929-53.

Loos R, Gawlik BM, Locoro G, Rimaviciute E, Contini S, Bidoglio G. EU-wide survey of polar organic persistent pollutants in European river waters. Environ Pollut 2009;157(2):561-8.

López-Roldán R, López de Alda MJ, Gros M, Petrovic M, Martín-Alonso J, Barceló D. Advanced monitoring of pharmaceuticals and estrogens in the Llobregat River basin (Spain) by liquid chromatography-triple quadrupole-tandem mass spectrometry in combination with ultra performance liquid chromatography-time of flight-mass spectrometry. Chemosphere 2010;80:1337-44.

Muñoz I, López-Doval JC, Ricart M, Villagrasa M, Brix R, Geiszinger A, et al. Bridging levels of pharmaceuticals in river water with biological community structure in the Llobregat river basin (northeast Spain). Environ Toxicol Chem 2009;28(12): 2706-14.

Nödler K, Licha T, Bester $\mathrm{K}$, Sauter $\mathrm{M}$. Development of a multi-residue analytical method, based on liquid chromatography-tandem mass spectrometry, for the simultaneous determination of 46 micro-contaminants in aqueous samples. J Chromatogr A 2010;1217:6511-21.

Nödler K, Licha T, Barbieri M, Pérez S. Evidence for the microbially mediated abiotic formation of reversible and non-reversible sulfamethoxazole transformation products during denitrification. Water Res 2012;46(7):2131-9.

Onesios K, Yu J, Bouwer E. Biodegradation and removal of pharmaceuticals and personal care products in treatment systems: a review. Biodegradation 2009;20(4):441-66.

Osorio V, Pérez S. Development of an analytical method to determine occurrence of Diclofenac, its Metabolites and its Transformation products in wastewater. In preparation.

Patterson B, Shackleton M, Furness A, Pearce J, Descourvieres C, Linge K, et al. Fate of nine recycled water trace organic contaminants and metal(loid)s during managed aquifer recharge into a anaerobic aquifer: column studies. Water Res 2009;44(5): 1471-81. 
Pereira R, Pereira L, van der Zee FP, Madalena Alves M. Fate of aniline and sulfanilic acid in UASB bioreactors under denitrifying conditions. Water Res 2011;45(1): 191-200.

Pérez S, Barceló D. First evidence for occurrence of hydroxylated human metabolites of diclofenac and aceclofenac in wastewater using QqLIT-MS and QqTOF-MS. Anal Chem 2008;80(21):8135-45.

Petrovic M, Eljarrat E, Lopez de Alda MJ, Barceló D. Endocrine disrupting compounds and other emerging contaminants in the environment: a survey on new monitoring strategies and occurrence data. Anal Bioanal Chem 2004;378:549-62.

Petrovic M, Lopez de Alda M, Diaz-Cruz S, Postigo C, J., R., Gros M, et al. Fate and removal of pharmaceuticals and illicit drugs in conventional and membrane bioreactor wastewater treatment plants and by riverbank filtration. Philos Trans R Soc A 2009;367:3979-4003

Preuss G, Willme U, Zullei-Seibert N. Verhalten ausgewählter Arzneimittel bei der künstlichen Grundwasseranreicherung - Eliminierung und Effekte auf die mikrobielle Besiedlung. Behaviour of some pharmaceuticals during Artificial Groundwater Recharge - elimination and effects on microbiology. Acta Hydrochim Hydrobiol 2001;29(5):269-77.

Rauch-Williams T, Hoppe-Jones C, Drewes J. The role of organic matter in the removal of emerging trace organic chemicals during managed aquifer recharge. Water Res 2010;44(2):449-60.
Scheytt T, Mersmann P, Rejman-Rasinski E, These A. Tracing pharmaceuticals in the unsaturated zone. J Soils Sediments 2007;7(2):75-84.

Schmidt C, Lange F, Brauch H-J. Assessing the impact of different redox conditions and residence times on the fate of organic micropollutants during riverbank filtration. Fourth International Conference on Pharmaceuticals and Endocrine Disrupting Chemicals in Water, October 13-15, 2004 - Minneapolis, Minnesota; 2004.

Ternes TA, Bonerz M, Herrmann N, Teiser B, Andersen HR. Irrigation of treated wastewater in Braunschweig, Germany: an option to remove pharmaceuticals and musk fragrances. Chemosphere 2007;66(5):894-904.

Tiehm A, Schmidt N, Stieber M, Sacher F, Wolf L, Hoetzl H. Biodegradation of pharmaceutical compounds and their occurrence in the Jordan valley. Water Resour Manage 2010:1-9.

Underwood JC, Harvey RW, Metge DW, Repert DA, Baumgartner LK, Smith RL, et al. Effects of the antimicrobial sulfamethoxazole on groundwater bacterial enrichment. Environ Sci Technol 2011;45(7):3096-101.

Yamamoto H, Nakamura Y, Moriguchi S, Nakamura Y, Honda Y, Tamura I, et al. Persistence and partitioning of eight selected pharmaceuticals in the aquatic environment: laboratory photolysis, biodegradation, and sorption experiments. Water Res 2009;43(2):351-62.
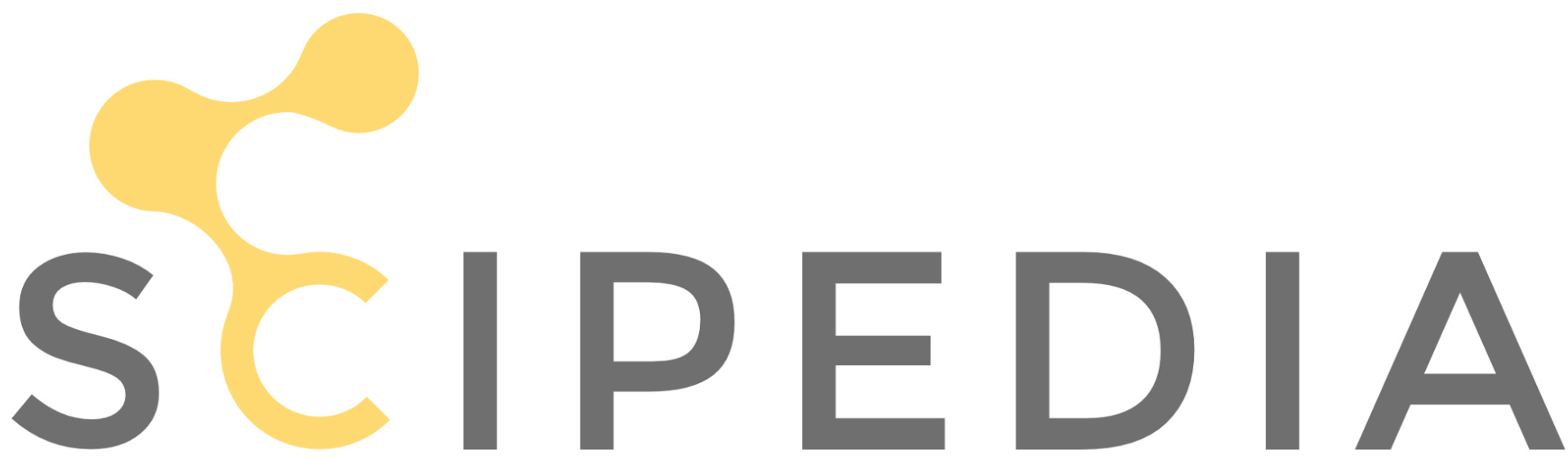

Register for free at https//www.scipedia.com to download the version without the watermark 